\title{
El Delito Con Rostro: \\ Los comienzos de la identificación de delincuentes en Uruguay
}

\section{Daniel Fessler ${ }^{1}$}

\begin{abstract}
Resumen
El presente artículo pretende analizar las tensiones existente a principios del siglo XX entre los dos grandes métodos de identificación de delincuentes ("bertillonaje" y dactiloscopia). En consonancia, se acentúa la necesidad de producir mecanismos eficientes de control, convirtiendo a la policía en una agencia cada vez más especializada que se encuentre en mejores condiciones de identificar y perseguir lo que se percibía como una creciente criminalidad. En la visión de los grupos dominantes, clases trabajadoras y peligrosas se confundirán desde su reclutamiento, incluyendo en este último núcleo a determinados sectores de inmigrantes y a los grupos visualizados como una nueva "delincuencia": la social.
\end{abstract}

Palabras claves: Uruguay; Historia; delito; métodos de identificación.

\section{O Delito com Rosto: Os primórdios da identificação de delinquentes no Uruguai}

\section{Resumo}

O presente artigo pretende analisar as tensões existentes entre os dois grandes métodos de identificação de delinquentes ("bertillonnage" e datiloscopia) no limiar do século XX. Em consonância, acentua-se a necessidade de produzir mecanismos eficientes de controle, convertendo a polícia em uma agência cada vez mais especializada e capaz de identificar e perseguir o que era considerada como uma criminalidade crescente. $\mathrm{Na}$ visão dos grupos dominantes, classes trabalhadoras e perigosas se confundiriam desde 0 seu recrutamento, incluindo neste último núcleo determinados setores de imigrantes e os grupos visualizados como una nova "delinquência": a social.

Palavras-chave: Uruguai, História, delito, métodos de identificação.

\section{Giving crime a face: The beginnings of identifying criminals in Uruguay}

\section{Abstract}

This article aims to analyze tensions at the beginning of the twentieth century between the two main methods of identifying criminal offenders ("bertillonnage" and dactyloscopy). It therefore highlights the need to produce efficient control mechanisms, converting the police into an increasingly specialized agency better placed to identify and pursue what was perceived as a growth in criminality. In the eyes of the dominant groups, working class and dangerous people are considered one and the same, with the latter nucleus including certain sectors of immigrants and groups seen as a new form of "crime": the social.

Keywords: Uruguay; history; crime; identification methods.

\footnotetext{
${ }^{1}$ Departamento de Historia del Uruguay, Facultad de Humanidades y C.E. - Universidad de la República (Uruguay). Investigador activo del Sistema Nacional de Investigadores de la Agencia Nacional de Investigación e Innovación (ANII) - Uruguay. E-mail: danfessler@gmail.com
} 


\section{Le délit de faciès: Ies débuts de l'identification des délinquants en Uruguay}

\section{Résumé}

Le présent article prétend analyser les tensions visibles au XX ${ }^{\mathrm{ème}}$ siècle entre les deux grandes méthodes d'indentification de délinquants (le «bertillonnage " et la dactyloscopie). En résonance, le besoin de produire des mécanismes de contrôle efficaces s'accentue, faisant de la police une institution toujours plus spécialisée et dotée de meilleures conditions pour l'identification et la répression de ce qui était perçu comme une criminalité croissante. Du point de vue des groupes dominants, les classes ouvrières et dangereuses n'ont toujours fait qu'une et comprennent en outre certaines populations immigrées et les groupes perçus comme constituant une nouvelle « délinquance » : la sociale.

Mots-clés : Uruguay ; Histoire ; délit ; méthodes d'identification.

\section{罪犯有了脸部识别：乌拉圭对罪犯的脸部辨别的初始阶段}

\section{摘要}

本论文旨在讨论 20 世纪初乌拉圭开始对罪犯实行人类学识别（人类测量学和指纹识别法）而

引发的一些紧张冲突。在当时的时代背景下, 需要一种有效的社会控制机制, 所以当时的警察就变成了社会控 制的专业人士，致力于对罪犯的追查和辨别，并且搜捕

罪犯, 打击犯罪, 减少犯罪率。在那时当权者眼里, 工人阶级和危险分子混为一谈, 危险分子还包括移民和一 些被认作危险分子的"新型"的违法人员：那些社会活动家。

关键词: 乌拉圭, 历史, 违法, 罪犯辨别方法。

\section{Introducción}

El anhelo de Jeremy Bentham a fines del siglo XVIII "de encontrar el modo de controlar todo lo que a cierto número de hombres les puede suceder"2 resume una de las máximas del aparato estatal a partir del siglo XIX.

El positivismo dotó a esa voluntad de control del Estado de formas de legitimación en base a una ciencia que fundamentaba el orden, la disciplina y la organización. En consonancia el control se lograba de manera pretendidamente objetiva y neutral, ocultando el carácter de una ideología de un Estado intervencionista. Esto hacía posible su radicalización en base a una división que se asumía como científica y que clasificaba a los hombres en peligrosos y no peligrosos. ${ }^{3}$ En una sociedad decimonónica marcada por una creciente movilidad, se debían adecuar los mecanismos de control establecidos,

\footnotetext{
${ }^{2}$ Bentham, Jeremy (2005). El panóptico, Bs. As.: Quadrata, p. 15.

${ }^{3}$ Bustos Ramírez, Juan (1983). "Estado y control: la ideología del control y el control de la ideología". In Bergalli, Roberto y otros (1983). El pensamiento criminológico, un análisis crítico, Bogotá, Temis, v. II, p. 16 y 17.
} 
sobre la base de un esquema bipolar de individuos normales y anormales. En defensa de la sociedad se procuraba detectar al peligroso social, oponiéndose a él procurando resocializarlo o por lo menos inoculizarlo. ${ }^{4}$

Así, el dominio ideológico de la criminología positivista consolidará el derecho penal de autor basado en la peligrosidad del delincuente que pautará todo el siglo XIX. De esta forma se desplazará del centro al delito, como hecho abstracto, para concentrarse en la biografía como un hecho medular. Pero esta biografía hará existir al criminal antes que el crimen. La aceptación generalizada de la teoría del "estado peligroso" que aísla a los sujetos que por su actividad o medio de vida presentan una predisposición a cometer delitos puso bajo sospecha a numerosas profesiones y grupos.

Se acentúa entonces la necesidad de producir mecanismos eficientes de control, convirtiendo a la policía en una agencia cada vez más especializada que se encuentre en mejores condiciones de identificar y perseguir lo que se percibía como una creciente criminalidad. Abolido el empleo del marcado o la mutilación como señal para la identificación de un delincuente, el mecanismo del conocimiento por parte de las instituciones de control se veía progresivamente erosionado por el crecimiento de las ciudades, o el traslado de aquellos que con el cambio de residencia o de nombre escapaban a una condena más severa. En el Río de la Plata, la importante corriente migratoria multiplica para el Estado el problema de lo desconocido percibido como sinónimo de peligro. La situación se agrava por el frágil vínculo a la tierra que los recibe, siendo frecuentemente una fuerza de trabajo con empleo precario y de intensa movilidad tanto ocupacional como espacial lo que dificultaba su control.

Todos estos riesgos, para los criminólogos positivistas, los hacía formar parte de la franja de aquellos que potencialmente podían abandonar el "mundo del trabajo" para incorporarse al "mundo del delito". 5 En la visión de los grupos dominantes, clases trabajadoras y peligrosas se confundirán desde su reclutamiento, ${ }^{6}$ incluyendo en este último núcleo a determinados sectores de inmigrantes y progresivamente desde principios del siglo XX a los grupos visualizados como una nueva "delincuencia": la social. La persecución de estos sectores, básicamente de extracción anarquista, deberá dar

\footnotetext{
${ }^{4}$ Foucault, Michel (2000). Los anormales, Bs. As.: F.C.E, p. 43.

${ }^{5}$ Salvatore, Ricardo (2004). "Criminología positivista, reforma de prisiones y la cuestión social/obrera en Argentina". In Suriano, Juan (Comp.) (2004). La cuestión social en Argentina 1870 - 1943. 2. ed., Bs. As.: La Colmena, p. 144.

${ }^{6}$ Gayol, Sandra; Kessler, Gabriel (2002). Violencias, delitos y justicias en la Argentina, Bs. As.: Manantial Universidad Nacional de General Sarmiento, p. 17.
} 
respuesta a las prácticas de traslados permanentes, incluso transoceánicos, como mecanismo de evadir la represión. Inicialmente la vigilancia del Estado se hará sobre estos grupos por la necesidad de ejercer un mayor y mejor control sobre los sindicados como peligrosos. Este se aplicará entonces en primera instancia sobre los sujetos que ya han delinquido para extenderse luego sobre sectores cada vez más amplios de la población.

El uso de la fotografía como soporte gráfico del conocimiento criminal fue muy importante al permitir que tanto el aparato policial como penitenciario contaran con un medio de control visual para aquellos delincuentes de mayor peligrosidad y también de los reincidentes. ${ }^{7}$ Su empleo puede insertarse en las tensiones en el seno de las agencias de control para lo obtención de los medios más eficientes a efectos de la mejor y más rápida identificación de los delincuentes en el combate contra "la marea roja del crimen".

Durante los primeros años del siglo XX se produjeron en Uruguay duras polémicas entre los defensores del método conocido como bertillonaje y los que sostuvieron el empleo de la dactiloscopia. Al igual que había ocurrido en Buenos Aires, los debates tuvieron como figura destacada a Juan Vucetich, creador y difusor del "Sistema Dactiloscópico Argentino" y encargado de la Oficina de Identificación de la ciudad de La Plata. Este método contó en Uruguay con la adhesión de Alejandro Saráchaga que se encontraba al frente de la Oficina de Identificación Dactiloscópica de la Jefatura Política y de Policía de Montevideo creada en el año 1905. Sarachaga tuvo intensas confrontaciones con Alfredo Giribaldi quien dirigía la Oficina de de Identificación y Antropometría anexa a la Comisaría de Investigaciones instalada con un Laboratorio Fotográfico en 1895 y apoyaba el empleo del sistema Bertillón.

El fuerte enfrentamiento no debe ser considerado solo como un debate de teorías enfrentadas sino que se encontraba subyacente una pugna interna entre servicios. Como lo sugirió Vucetich del éxito argumental y de la consolidación de posiciones dependía el mantenimiento mismo a las Oficinas Antropométricas de Montevideo y Buenos Aires. Estas ya sufrían importantes cuestionamientos en los medios intelectuales vinculados a la práctica forense. De esta manera la polémica estuvo marcada por un discurso científico

\footnotetext{
${ }^{7}$ Leon Leon, Marco Antonio (1999-2000). “Una impresión imborrable de su personalidad”. La fotografía carcelaria y la identificación criminológica en Chile (1870 - 1940)". In Revista Chilena de Historia del Derecho, n. 18, Centro de Investigaciones de Historia del Derecho, Facultad de Derecho de la Universidad de Chile, Santiago, p. 311 a 333.

${ }^{8}$ Ramos, Juan P. cit. por De Arenaza, Carlos (s.d). Hogar de preservancia, p. 188 y 189.
} 
que trascendió el tratamiento de determinado tipo de imágenes (y su efectiva aplicación a una causa) contemplando cuestiones como la idoneidad técnica para el combate de la criminalidad.

El recorrido de la imagen de las tarjetas de visita a los gabinetes antropométricos de las prisiones y las oficinas policiales, y de allí a los documentos de identidad (con aceptada presencia de la fotografía y la impresión de huellas antes restringida al fichaje de identificación criminal) parece evidenciar una red cada vez más amplia de control de la sociedad.

\section{Un sujeto particular: el delincuente (Un ser peligroso)}

El primer Congreso de Antropología Criminal de 1885 representó la primacía de la escuela positiva sobre la clásica marcando un giro radical en la visión del delito y la delincuencia. De esta forma la criminología se ajusta a la visión universal del orden. Como ciencia que puede conocer leyes que regulan los hechos, incluso los sociales, es capaz de establecer el orden en la sociedad. ${ }^{9}$ A partir del Congreso de 1885 se evidenciaron las posiciones deterministas que mostraron al infractor como un ser absolutamente condicionado por factores del orden antropológico y sociológico. En el primer núcleo, la tendencia al delito se debía a ciertas particularidades individuales del criminal. Este se encontraba potencialmente inclinado a llevar adelante un comportamiento "socialmente desviado".

Estos planteos fueron desarrollados por Cesare Lombroso, especialmente en su obra "El hombre delincuente" y por Rafaello Garofalo particularmente en su "Criminología". Entre sus premisas esenciales se comparaba al delito con un ente natural (asimilable al nacimiento y a la muerte) determinado por causas de carácter fundamentalmente hereditario. El delito, posibilitaba descubrir una "naturaleza degenerada", poniendo de manifiesto la "anomalía moral". De todas maneras, este en forma aislada no permitía un conocimiento absoluto sino que era indispensable la observación, dado que los delincuentes son seres distinguibles del resto de la sociedad

\footnotetext{
${ }^{9}$ Bustos Ramírez, Juan (1983). "Criminología y evolución de las ideas sociales". In Bergalli, Roberto y otros (1983). El pensamiento criminológico, un análisis crítico, Bogotá: Temis, v. I, p.34.
} 
por sus caracteres especiales: "esto sólo puede negarlo quien no haya puesto nunca el pie en una cárcel ni en un presidio". 10

Los representantes de la vertiente biológica destacaron la existencia de dos características fundamentales: la forma y proporción de la cabeza. En los delincuentes es anómala con más frecuencia que en el ciudadano normal, y en los que cometieron crímenes más graves se encuentran las malformaciones más reiteradamente que en los autores de ilícitos de menor cuantía. Se llegaba a una clasificación pormenorizada por la que cada una de las tres grandes especializaciones criminales -asesinos, violadores y ladrones - tenía una fisonomía especial con caracteres determinados y fácilmente reconocibles. Además, sin llegar a presentar signos de deformidad, sería un elemento identificatorio la extrema y "repugnante" fealdad que es común en las cárceles, particularmente entre las mujeres, no observándose entre las mismas facciones regulares y expresiones dulces.

La visión sociológica de Enrico Ferri, sin descartar los componentes biológicos, amplió estas perspectivas con las influencia del medio como generador de una "formación defectuosa" que terminará repercutiendo en su inserción en la "vida social":

Verdad es que los adversarios de la antropología criminal después de visitar las prisiones y los manicomios, afirman no haber encontrado criminales de caracteres específicos; pero esto lo que prueba simplemente es que no han sabido buscarlos, porque, mucho más juristas que antropólogos, ni tenían conocimientos suficientes ni experiencia científica ${ }^{11}$

A partir de Ferri, el predominio de uno u otro elemento posibilitaba una clasificación primaria distinguiendo entre delincuentes natos (biológicos) quienes orientarán sus acciones a hechos violentos y ocasiones (sociales) movidos hacia delitos contra la propiedad. La determinación precisa por los técnicos sería un componente esencial pues orientaría los grandes lineamientos del futuro tratamiento que llevaría a la rehabilitación.

La criminología positivista al haber asumido como base que la cualidad criminal existe como un hecho objetivo, determinará que la identificación y la clasificación tengan un rol esencial en la lucha contra "la ola creciente de criminalidad" ${ }^{12}$

\footnotetext{
${ }^{10}$ Garofalo, Rafaello (1912). La Criminología, estudio sobre la naturaleza del crimen y teoría de la penalidad. Madrid: Daniel Jarro, p. 72.

${ }^{11}$ Ferri, Enrico (s.d.) Sociología criminal, Madrid: Centro Editorial de Góngora, p. 73.

12 Ibidem, p. 5.
} 
Clasificar, era una forma de ordenar y controlar "la incontrolable realidad". Clasificar delincuentes, conllevaba una manera de desactivar, aún simbólicamente, parte del peligro para el resto de la sociedad: "una intervención gráfica que anticipaba las promesas de defensa social de la nueva ciencia". 13

Es además, sobre los delincuentes que se comenzaron a desarrollar las primeras técnicas identificatorias, particularmente en los gabinetes instalados en las prisiones, para luego extenderse al resto de la sociedad buscando ampliar los mecanismos de control de una población cada vez más numerosa y anónima. Así, una constante desde el siglo XIX fue el progresivo aumento de "la memoria del Estado, de tal forma, que ha creado un entramado que le permite, identificar automáticamente a los individuos y sus actos más relevantes". ${ }^{14}$

\section{La imagen al servicio de la identificación (Frente a la máquina)}

A partir de mediados del siglo XIX la fotografía comenzó a ser utilizada como un elemento idóneo para la identificación manifestándose por lo menos en dos grandes líneas.

Un empleo social, que tuvo que ver con el uso de las tarjetas de presentación conocidas como "Cartes de Visite". Su extensión se relacionó con los cambios tecnológicos que permitieron la reducción de los precios de las impresiones facilitando su popularización. Particularmente la innovación introducida por André Disderí que posibilitaron la realización de diez fotografías a partir de un negativo único. De esta forma se obtenían retratos de unos $7 \mathrm{~cm}$ de alto por $5 \mathrm{~cm}$ de ancho que luego se adherían a una cartulina. ${ }^{15}$

Una segunda línea propuso integrar el retrato a la vasta red del sistema judicial por medio de la creación de grandes ficheros que incluyeran hospitales y penitenciarias. Pero mientras que las "Cartes de Visite" expusieron al sujeto rodeado de objetos minuciosamente seleccionados con el fin de divulgar una imagen que procuraba ser

\footnotetext{
${ }^{13}$ Caimari, Lila (2004). Apenas un delincuente. Crimen, castigo y cultura en la Argentina, 1880 - 1955 , Bs. As.: S. XXI editores, p. 93.

${ }^{14}$ Trinidad Fernández, Pedro (1991). La defensa de la sociedad. Cárcel y delincuencia en España (siglos XVIII-XX), Madrid: Alianza, p. 285.

${ }^{15}$ Rojas Martínez, José Luis (1997). Las tarjetas de visita, popularización del retrato fotográfico en el México del siglo XIX. Disponible en: <www.mexicodesconocido.com>. Consultado el 20 de julio de 2014.
} 
apreciada por los demás, el retrato judicial, de cierta manera, apareció como su contrario, realizándose con un fin clasificatorio y de control estatal. ${ }^{16}$

Para ello fue necesario desarrollar métodos que cumplieran con el objetivo elemental de la precisión a efectos de facilitar la identificación, especialmente de los reincidentes. Con la ampliación de su uso se hizo insoslayable la fijación de pautas de estandarización. Estas hacían posible tanto la comparación entre los objetos a relacionar como el cruzamiento de información a nivel nacional entre las diferentes regiones y oficinas. No es casual que tempranamente, en 1872, la policía francesa creó su servicio fotográfico. Diez años después, desde el Servicio Fotográfico de la Prefectura de París, Alphonse Bertillon estableció un protocolo que luego sería conocido como "Sistema Bertillon" o más frecuentemente como bertillonage. Inicialmente el sistema combinaba dos elementos básicos, la antropometría y la fotografía. ${ }^{17}$ Se basaba en la estabilidad del esqueleto humano a partir de los 25 años y la diversidad entre las distintas personas la que se ponía de manifiesto en la toma de las medidas dotando a cada sujeto de una identidad propia. En 1888, en la Prefectura de Policía de París, Bertillon instaló una sala especialmente preparada para el área antropométrica. En ella se incorporó el instrumental necesario para la toma de mediciones (cráneo, extremidades y busto) destacándose un "compás de espesores". Este constaba para su fijación de tornillos en las ramas, procurando evitar errores fruto de los movimientos, provocados no sólo por la impericia de quien lo empleaba sino inducidos en algunas oportunidades por los delincuentes consumados. $^{18}$

Bertillon tenía conciencia de que el éxito del archivo fotográfico se encontraba íntimamente relacionado con que cada uno de los objetos sean reproducidos siguiendo una metodología absolutamente precisa. Como señala en su obra, en París "los archivos fotográficos se manejan rigurosamente, con reglas idénticas". ${ }^{19}$ Por ello era necesario

\footnotetext{
${ }^{16}$ De La Cruz lichet, Virginia (2004). Miradas enfrentadas (Indagaciones sobre la identidad a través del retrato fotográfico, 13 de diciembre, Universidad Complutense de Madrid, Seminario. Disponible en: <www.ucm.es >. Consultado el 15 de julio de 2014.

${ }^{17}$ Posteriormente incorporará la dactiloscopia. Esta será tomada por los defensores este sistema como un reconocimiento tácito del fracaso de su método por parte de A. Bertillon.

18 Speckman Guerra, Elisa (2001). La identificación de criminales y los sistemas ideados por Alphonse Bertillon: discursos y prácticas (Ciudad de México 1895 - 1913), p. 9. Debo el presente trabajo a su autora. El Servicio empleaba también la silla, conocida con el nombre de su creador, donde se sentaba el detenido a efectos de la toma de su fotografía. La silla era mantenida a una distancia fija y mediante el mecanismo de un giro de noventa grados posibilitaba la toma de frente y de perfil. Con el uso de un apoya cabeza se evitaba la movilidad que generaba una distorsión en la imagen del indagado. Esto permitía reproducir al objeto según una constante que se promovería para todos los gabinetes antropométricos.

${ }^{19}$ Bertillon, Alphonse (1890). Cómo se debe realizar un retrato judicial. Disponível em: www.educ.ar.
} 
precisar con la mayor minuciosidad aspectos técnicos como la luz, la distancia, el tipo de objetivo, el formato a adoptar y el fondo empleado. Este último debía ser neutro, colocándose habitualmente una tela blanca, lo cual generaba una imagen recortada, quitándole expresividad y contextualización. ${ }^{20}$ El propósito resultaba elemental. Para Bertillon se trataba de lograr que la reproducción tuviese la mayor fidelidad posible, generando una imagen que comparada con el original fuese de fácil identificación.

Se debía tomar de cada ser humano los "trazos más exactos" a efectos de poder cotejarla con las fotografías conservadas en expedientes judiciales y archivos carcelarios desarticulando los problemas que causaban el pasaje del tiempo y las propias formas de observación por parte del testigo (tanto el ángulo desde donde mira hasta el recuerdo mismo). De esta manera la incorporación del uso de la fotografía de frente y de perfil procuró resolver estos inconvenientes El empleo de este último plano aportaba datos fundamentales como la oreja que brindaba "miles de particularidades preciosas" sobre todo en lo que hace a la identificación transcurridos varios años desde la fotografía inicial. La utilización de ambas tomas pretendió aunar las ventajas para el reconocimiento que proporcionaba cada posición: "si las poses de perfil son las preferidas para la identificación lineal, la experiencia demuestra que los retratos de frente son mejor reconocidos tanto por el sujeto como por el público". 21

Contrariamente a lo que ocurría con la fotografía social, la imagen incorporada a la práctica forense debía evidenciar las imperfecciones del individuo. Lejos de ocultarlas, tenía que poner de manifiesto arrugas, pliegues de la piel, cicatrices y todo elemento que aportase datos para la identificación. De esta forma funcionaba en sentido opuesto de la fotografía social, que con la técnica del retoque eliminaba todos los detalles desagradables que la exposición no conseguía disimular. ${ }^{22}$ La captación de estos "rasgos esenciales" contribuyó a la confirmación de la imagen del delincuente como un individuo particular, con señales que lo identificaban, como sostenía la criminología positivista. Como señala Gisèle Freund, lejos de la pretendida imparcialidad, esta fotografía permite

20 Giraudo, Silvia; Arenas, Patricia (2004). Científicos europeos en el altiplano boliviano-argentino: antropología, expedición y fotos, Instituto de Arqueología y Museo. Universidad Nacional de Tucumán en Anales del Museos de América, p. 126.

${ }^{21}$ Bertillon, A. (1890). Op. Cit., p. 5.

${ }^{22}$ Freund, Gisèle (1946). La fotografía y las clases medias en Francia durante el siglo XIX, Bs. As.: Losada, p. 93. 
todas las deformaciones posibles de la realidad, dado que el carácter de la imagen está condicionado por la manera de ver del operador. ${ }^{23}$

Bertillon no sólo aportó a las técnicas de identificación criminal propiamente dicha, sino que se adentró en el problema del manejo de la información proporcionada desde los gabinetes. La cuestión archivológica no era un tema menor pues las policías se planteaban como resolver la suma de información obtenida, que por su propio volumen terminaba por hacer ineficaces los intentos de reconocimiento. Bertillon, diseñó un método de clasificación de las imágenes existentes en los archivos policiales que permitía encontrar una fotografía entre miles como ocurriera con las 75.000 imágenes de la Prefectura de París. La solución llegó a través de la instrumentación de una "ficha" en donde se combinaba la fotografía con una descripción resumida de medidas y rasgos, para luego organizarlas en un sistema de archivo seriado en divisiones sucesivas. ${ }^{24}$ Se trataba básicamente de organizar grupos, iniciando con una primera repartición según el sexo y a partir de allí subdivisiones por estatura, tamaño de cabeza, longitud de pie y dedo medio izquierdo y el correspondiente antebrazo y el color de ojos. Se obtuvieron de esta forma unos cincuenta grupos lo que permitía una búsqueda rápida y sencilla.

Precisamente este fue el nudo de la discusión, pues en la eficacia de su aporte al aparato del Estado en el combate a la delincuencia se encontrarían los motivos de su cuestionamiento y posterior declive. Progresivamente, los métodos de Bertillon comenzaron a ser severamente criticados y su resquebrajamiento se produjo a partir de la introducción de la dactiloscopia. Si bien, la misma había tenido sus primeros pasos en Asia y Europa ${ }^{25}$, el Río de la Plata tuvo en Juan Vucetich uno de sus más importantes sistematizadores.

\section{La identificación eficiente}

Los avances del sistema dactiloscópico y la suma de adhesiones multiplicaron las críticas al aporte a la investigación criminal de la fotografía. Fundamentalmente bajo la premisa de que está solo servirá parcialmente por su incapacidad de acompañar los

\footnotetext{
${ }^{23}$ Ibidem, p. 12.

${ }^{24}$ López Rodríguez, José Ramón (1992). “Procedimientos de archivo”. In Revista Photovision, n. 24, p. 614. Disponible en: <www.museodeandalucia/textos>. Consultado el 3 de julio de 2014.

25 Luego de su jubilación Vucetich tendrá oportunidad de recorrer varios de los países señalados habitualmente como iniciadores del uso de la dactiloscopia. En comentarios posteriores pondrá en entredicho la habitual afirmación que los establece como pioneros relativizando sus aportes.
} 
cambios fisonómicos naturales o artificiales. Esta situación se agravará cuando el delincuente reincidente conciente del empleo de la fotografía como herramienta policial procurará camuflar su identidad a efectos de evadir su captura. ${ }^{26}$

Pese a ello algunos de los criterios fijados por Bertillon, especialmente a lo que hace al uso de la imagen de frente y perfil, no desaparecerán. Su empleo se mantuvo inclusive luego de la aparición de los primeros trabajos sobre el uso de las huellas dactilares. A partir de algunas experiencias de la India, Francis Galtón realizó un primer intento de aplicación que fue difundido por Henry de Varigny en la "Revue Scientifique". Traducido al español en la "Revista de Identificación y Ciencias Penales" sirvió de inspiración a Juan Vucetich, encargado de la Oficina de Identificación de La Plata. ${ }^{27}$

Los progresos de su método implico un proceso de transición con los procedimientos ya instalados. Sus avances no estuvieron exentos de tensiones con los organismos de identificación que practicaban el sistema antropométrico que derivó en la supresión del servicio en 1893.

En los hechos, los primeros trabajos de Vucetich fueron incorporando progresivamente la dactiloscopia. El "Sistema de Filiación de la Provincia de Buenos Aires" todavía no abandonaba las técnicas tradicionales que procedían a efectuar anotaciones particulares como el perfil y la forma de la nariz y la descripción de tatuajes y cicatrices. Se dará preferencia a estas últimas sobre las primeras por su carácter invariable clasificándolas según sus tipos (cortantes, punzantes, contundentes, de arma de fuego). Finalmente, retoma las pautas para el registro fotográfico con una serie de instrucciones para su aplicación en la indagatoria judicial. Se mantiene el uso de la toma de frente y de perfil, especificando el uso de "reglitas" para determinar la proporcionalidad a efectos de una correcta interpretación. Su obra incorporaba principios de un sistema de identificación que se basaba en el análisis de las huellas. Estudiando una impresión digital se podrá encontrar dibujos con formas diferentes que Vucetich dividió en tres zonas delimitadas por líneas a las que llamó directrices. El sistema se apoyó en el estudio de un delta que determinaba toda la clasificación en razón del número existente que variaba de uno a varios (incluso podía llegar a no existir). Para posibilitar su identificación

\footnotetext{
${ }^{26}$ Sánchez Vigil, Juan M.; Fernández Fuentes, Belén (2005). "La fotografía como documento de identidad". In Documentación de las Ciencias de la Información, v. 28, p. 190 y 191. Disponible en: <www.ucm.es>. Consultado el 8 de julio de 2014.

${ }^{27}$ Turnes, Antonio (2005). "Cien años de la dactiloscopía en Uruguay". In Suplemento de Derecho Médico Disponible en: <www.ddu.com $>$. Consultado el 25 de julio de 2014.
} 
instrumentó un sencillo sistema que empleaba las letras A, I, E y V para los pulgares, numerando del 1 al 4 los restantes dedos. Este mecanismo básico posibilitaba subsanar uno de los grandes problemas de la identificación consistente en encontrar una ficha entre miles de muestras.

La defensa de la técnica se basó en dos principios generales: las huellas son inmodificables (por lo que acompañaran al individuo durante toda su vida), y no se reitera las impresiones digitales en dos sujetos.

Las críticas recibidas por Vucetich, en particular las del Jefe de la Oficina de Antropometría de la Capital Federal Dr. Agustín Drago, fueron el preámbulo de las duras polémicas que se sostendrá en ambas orillas del Río de la plata. Si bien Drago en el artículo aparecido en "La Nación" en 1895 descalificó el trabajo del Vucetich por considerarlo un plagio a la obra de Bertillon ${ }^{28}$, la evolución de los trabajos del croataargentino en dirección a la dactiloscopía, llevaron el enfrentamiento a un debate de corte científico. Este se concentrará especialmente en la capacidad de ambos sistemas en el combate al delito y la delincuencia.

El sistema de Vucetich conseguirá probar su eficiencia aplicada a casos concretos. En 1892 logró esclarecer un doble filicidio ocurrido en Necochea en 1892 aplicando el método al rastro dactilar encontrado en la puerta probando la culpabilidad de la madre y la inocencia del vecino acusado. Tras la reiterada aplicación en la investigación policial y un largo proceso de experimentación, Vucetich avanzó en el rompimiento radical con los planteos de Alphonse Bertillon y sus seguidores. Fundamentalmente en lo que hace a las mediciones. Este tuvo consecuencias directas al suprimirse en 1896 la utilización de los procedimientos de la antropometría en la Oficina de Identificación de La Plata.

Los avances de sus planteos (tanto en lo teórico como en el posicionamiento administrativo) provocaron la agudización de las tensiones con las distintas oficinas antropométricas que sustentaban su existencia en la vigencia teórica del método de Bertillon y en su valor científico.

La conferencia de Vucetich en la Biblioteca Pública de La Plata marcó los ejes fundamentales del debate al destacar unas virtudes de la dactiloscopía que llevaron incluso al padre del bertillonaje a incorporarlo en 1894 a su método:

\footnotetext{
${ }^{28}$ Sappietro, Eugenio L. (2000). "El sistema dactiloscópico argentino”. In Studia Croatica, n. 141. Disponible en: <www.studiacroatica.com>. Consultado el 25 de julio de 2014.
} 
Al mismo tiempo, veíamos á Bertillon, malogrado los recelos y susceptibilidades de su fama amenazada, incorporarlos á su sistema.

Después de haber obtenido, en la práctica exclusiva de la identificación digital, pruebas incontestables de su eficacia, nuestras cavilaciones primeras se convirtieron en un convencimiento tan profundo, que hoy nos atrevemos á sostener que el sistema dactiloscópico, en la identificación es más eficiente que el procedimiento antropométrico. ${ }^{29}$

La conferencia resumirá las críticas fundamentales que lo llevarán a abandonar un sistema "que a pesar de sus indiscutibles ventajas, adolecía, para difundir su aplicación, de ciertos defectos é inconvenientes que perjudicaban la eficiencia del método y la absoluta exactitud atribuida al procedimiento antropométrico". ${ }^{30}$

Sus cuestionamientos se podrían dividir en dos grandes grupos. El primero fue inherente al sistema de Bertillon y radicaba esencialmente en los problemas que ocasionan las alteraciones que sufre el cuerpo humano con el pasaje del tiempo y otras influencias. Mientras que el color de la piel y el cabello, la expresión, los rasgos, los gestos y hasta la coloración de los ojos cambia con la edad, el dibujo dactilar "desde la existencia uterina hasta la putrefacción cadavérica"31 permanece invariable, incluso mediando accidentes y quemaduras. También se debía tener presente las dificultades para efectuar una verificación en archivos para sujetos menores de 21 años y la imposibilidad absoluta para aquellos por debajo de los 18 sin el empleo de la fotografía del perfil derecho.

Agregaba a ello un problema que resultó medular y que llevó incluso a hacer estéril el esfuerzo de los distintos gabinetes: el problema de la toma de datos. Se sumaban a la propia complejidad de la realización del estudio antropométrico, que la impericia o el error del personal -no siempre especializado- indujese "irremisiblemente al error". ${ }^{2}$

\section{Bertillonaje contra dactiloscopia: la polémica en Uruguay}

El debate que había tenido fuertes tensiones en Argentina, sede de la primera Oficina de Identificación Antropométrica de América Latina, tomó en Montevideo particular dureza transformándose en los hechos en un enfrentamiento personal entre los directores

\footnotetext{
${ }^{29}$ Vucetich, Juan (1901). Conferencia sobre el sistema dactiloscópico dada en la Biblioteca Pública de La Plata, La Plata, s/e, p. 13. A efectos de divulgar el sistema de Vucetich el Jefe de Policía de la Provincia de Buenos Aires Juan Ocampo, autorizó la edición de mil ejemplares de la conferencia.

${ }^{30}$ Ibidem, p. 6 y 7.

${ }^{31}$ Ibidem, p. 9.

32 Ibidem, p. 15.
} 
de las oficinas locales de Antropometría y de Identificación Dactiloscópica. La discusión involucró al propio Vucetich que participó en la polémica mediante una extensa nota aparecida en el diario "El Día” el 13 de noviembre de 1905. Está será una réplica a la obra de Alfredo Giribaldi "Identidades y filiaciones" publicada ese mismo año y donde se hace "vacilar por lo menos a los neófitos en uno de los más trascendentes problemas de actualidad para la policía moderna, como es la identificación personal, absolutamente resuelta en nuestros días por el Sistema Dactiloscópico". 33

En su artículo en el periódico montevideano Vucetich no sólo cuestionó la descalificación infundada de su sistema "absolutamente superior a otro", sino que denunció a Giribaldi por su "necesidad de defender el sistema antropométrico... por conveniencia y no por convicción" dado que tiene su andamiaje montado. La implantación de un método moderno, y no "un medio auxiliar de identificación", es incompatible con el "antiguo" 34 por lo que no quedaría espacio para la pervivencia de las viejas oficinas sin que medie su transformación. El Dr. Alfredo Giribaldi a su vez refutará este artículo y el trabajo del Dr. Alejandro Sarachaga "Dactiloscopía y convenio internacional de policía" en una nueva obra titulada "Contribución al tópico médico-legal de la identidad. Extracto de una polémica".

Esta confrontación entre ambos sistemas, que se repite regularmente en los países con oficinas de identificación instaladas, se agudizó en Montevideo a partir de la realización del Segundo Congreso Científico Latinoamericano en 1901. En este congreso, Juan Vucetich presentó su "Nuevo sistema de identificación" y obtuvo el reconocimiento al conseguir que entre las resoluciones del evento se propusiera su adopción a nivel continental. ${ }^{35}$

En Brasil se volverá a plantear la discusión sobre ambos métodos. El tema será centro de debates en el Congreso realizado en Río de Janeiro en 1905 en el cual Vucetich presenta su trabajo "Evolución de la Dactiloscopía" donde se formula la interrogante sobre cual es el método más adecuado para la identificación de delincuentes

\footnotetext{
${ }^{33}$ EL DÍA (1905), Montevideo, 13/11.

34 Ibidem.

${ }^{35}$ Así, en Río de Janeiro, capital de Brasil se instrumenta rápidamente cuando el decreto 4746, adopta el sistema dactiloscópico Vucetich el 5 de febrero de 1903, regulando la Ley 947 del 29 de diciembre de 1902. Medio año antes, el Estado de San Pablo inauguraba el Gabinete de Identificación Antropométrica con un laboratorio de fotografía como elemento auxiliar. Bombonatti, José (s.d.). Impressoes digitais. História da Dactiloscopia. Disponible en <www.coletoresimpress.com.br>. Consultado el 13 de julio de 2014.
} 
reincidentes. ${ }^{36} \mathrm{Si}$ bien las conclusiones aprobadas destacarán las ventajas en la ejecución de la dactiloscopía, se mantendrá el debate sobre las dificultades operativas del sistema para su ejecución por la policía. Este fue uno de los argumentos centrales del Dr. Alfredo Giribaldi.

\section{En defensa de lo que se puede ver}

Si bien el debate entre los actores en la defensa de los sistemas estuvo pautado por un marcado tono científico no se encontró exento de elementos que evidenciaron los intereses que se encontraban en juego. Sin estos, seguramente, no se entendería completamente la dureza de una confrontación que no negaba enteramente el método al que se oponía, sino que lo relegaba a la condición de un elemento auxiliar del que consideraba debía regir los sistemas de identificación.

La obra inicial de Giribaldi, publicada con el apoyo del Consejo Penitenciario, aspiraba a posicionarse a través de lo que consideraba un comprobado rigor científico. A ello sumaba las ventajas de la experiencia práctica que proporcionaba una oficina promocionada por su nivel de organización y una calidad demostrada. Estas servían para ratificar las virtudes ya probadas del sistema de Bertillon:

De la dactiloscopía...no combato sino la precipitación un tanto fanática de sus partidarios, que sin antecedentes investigativos suficientes, y sin el apoyo de una vasta experimentación preliminar, se esfuerza por desmonetizar, antes de tiempo, un sistema como el bertillonaje, controlado por el ensayo eficiente de muchos años. Creo que el rol de la dactiloscopía debe ser por ahora el de complementar el bertillonaje. ${ }^{31}$

Las críticas al sistema dactiloscópico incorporaron los cuestionamientos a su creador negando su calidad científica (golpe que asume Vucetich en su artículo en el diario "El Día" ${ }^{38}$ ). Por este mecanismo es reducido a un artesano que pese a su dedicación de veinte años no lograr realizar los niveles de generalización y abstracción propios de la

\footnotetext{
${ }^{36}$ Turnes, A. (2005). Op. Cit.

${ }^{37}$ Giribaldi, Alfredo (1905). Identidad y filiaciones, Mdeo.: Barreiro y Ramos, p. 5 y 6.

38 "Para cuantos puedan sentirse influenciados por un título académico, diré que no soy doctor; no he podido estudiar seis años de medicina, ni seis años de derecho". Sin embargo, señala Vucetich, que durante 20 años se ha dedicado a trabajar"el importante problema de la identificación personal, lo he estudiado y lo he resuelto". EL DÍA (1905), Mdeo., 13/11.
} 
ciencia. La verdad científica, señalaba Giribaldi, muchas veces se encuentra en la "conciliación racional" evitando todo "influjo exclusivista". 39

De esta forma, la dactiloscopía aportaba elementos, especialmente en el reconocimiento de cadáveres, que agregados a los de la antropometría de Bertillon presentaban un sistema más completo. La propia afirmación de Giribaldi será por él mismo relativizada en el momento de anotarse la dactiloscopía un acierto al identificar un cuerpo aparecido en Avellaneda y que el "Boletín de la Policía" de Buenos Aires titulo "Nuevo triunfo de la dactiloscopía". El intercambio de las fichas con las huellas dactilares entre las policías provinciales permitió determinar que el cadáver correspondía a Thomas Devis o Thompson.

Sin embargo, sostenía, la eficacia del sistema de Vucetich en esta área era inversamente proporcional al tiempo de exposición del cuerpo pues la putrefacción impedirá la extracción de las muestras que permitan su identificación. No debe olvidarse, señalaba Giribaldi, que para la identificación se necesita "algo de mayor importancia que el rodillo y la tinta, se necesita la piel".

En contraposición a la velocidad de descomposición de los tejidos blandos, los datos para establecer la identidad que proporciona el esqueleto permanecen: “¡cómo lamentaremos entonces nuestra falta de previsión y de práctica de la Antropometría!. ${ }^{40}$

Pero para hacer posible el confinamiento de la dactiloscopía a la condición de auxiliar, Giribaldi realizaba un estudio minucioso del bertillonaje partiendo de una lectura distinta de las resoluciones de los Congresos Latinoamericanos, achacando a Vucetich una interpretación errónea e interesada de las mismas. El método de Bertillon con la ejecución técnica y la capacitación del personal adecuada seguiría siendo, por sí solo, el sistema más completo. Para ello las oficinas adecuadamente dotadas, con la dirección de un médico, realizan la descripción metódica de las zonas visibles del cuerpo, la anotación "escrupulosa" de las anomalías que eran procesadas con rapidez de acuerdo con las abreviaturas ideadas por Bertillon, la medición antropométrica, y la fotografía de frente y

\footnotetext{
${ }^{39}$ Giribaldi, A. (1905). Op. Cit., p. 6.

40 Giribaldi, Alfredo (1906). Contribución al tópico médico-legal de la identidad. Extracto de la polémica, Mdeo.: El Siglo llustrado, p. 18. Sin embargo, en setiembre de 1895 Vucetich logra identificar un cadáver en estado de descomposición aparecido en una habitación en las calles 60 y 3 de la ciudad de La Plata. Se trataba de Carlos Casali, quien se había suicidado provocándose un corte en la garganta. Cotejadas las muestras obtenidas con las fichas dactiloscópicas del casillero de la Oficina de La Plata coincidió con huellas que habían sido obtenidas en la prisión de Sierra Chica en 1893.
} 
perfil "científicamente hecho y obedeciendo á reglas fijas, tan indispensables en tales condiciones para el pesquisante". 41

Precisamente las dificultades prácticas para una identificación rápida durante la pesquisa judicial fue una de las cuestiones más largamente debatidas. En primer lugar el problema de la obtención correcta de la imagen. Los dactiloscopistas insistían en la sencillez de la extracción de las huellas y la universalidad de la aplicación (no sólo

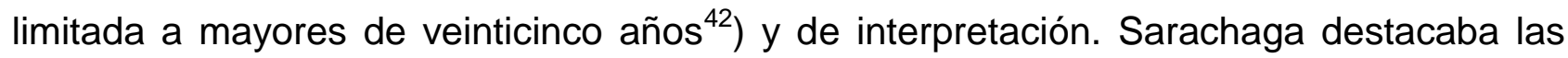
ventajas del sistema dactiloscópico ideado por Vucetich:

Exactitud matemática. Los dibujos digitales de un sujeto serán siempre idénticos á si mismo, cualquiera que sea el tiempo transcurrido, y distintos de los de cualquier otro sujeto. Aquí no hay margen de tolerancia porque no hay error posible, cuando el sujeto pone sobre el papel sus dedos entintados. ${ }^{43}$

Esta se contrapone con la complejidad tanto del procedimiento del bertillonaje como de las dificultades de su lectura:

En el sistema antropométrico, se toman minuciosas y numerosas medidas susceptibles de error, y la identidad directa sólo se establece con la descripción del sujeto, descripción que dependiendo del criterio personal de cada operador, puede variar en más o menos en el mismo sujeto. Hay que agregar la fotografía, cuyo valor deja mucho que desear como medio de identificación. ${ }^{4}$

Pese a los cuestionamientos al empleo de la fotografía el sistema de Vucetich nunca lo descartará. Al igual que ocurrió con el bertillonaje su uso aportaba datos complementarios para la identificación. La ficha modelo, elaborada para el canje de antecedentes de individuos peligrosos entre las policías regionales, cuyo acuerdo firman entre otros Juan Vucetich y Alejandro Saráchaga, además de la "individualidad dactiloscópica, según el sistema Vucetich", debía proporcionar los antecedentes judiciales y mantener la descripción morfológica utilizando el protocolo conocido como sistema "Provincia de Buenos Aires".

La fotografía se estandarizaría manteniendo el registro de la cara de frente y de perfil en placas de 9 por 13

\footnotetext{
${ }^{41}$ Giribaldi, A. (1905). Op. Cit., pp. 12 y 13.

42 Giribaldi también incorporaba a los grupos excluidos por "una noción elemental de pudor...al sexo débil". Ibidem, p. 32.

${ }^{43}$ Sarachaga, Alejandro (1906). Dactiloscopía y convenio internacional de policía, Mdeo.: El Siglo Ilustrado, p. 34 y 35 .

44 Ibidem.
} 
procurando cada Policía tomar todas las fotografías á una distancia uniforme, de modo que los tamaños de las imágenes, guarden entre sí proporción al tamaño real de los individuos fotografiados; cuidando de que la imagen de la cabeza no pase de 32 milímetros medidos de la línea superior del pelo á la base del mentón. ${ }^{45}$

Sobreviven sin dudas de las premisas de Bertillon la modificación de "los procedimientos de los fotógrafos artistas, llevándolos á respetar la naturaleza”. Se continuó reconociendo el valor del retrato de perfil, que reducía los efectos evasores de la identidad como la "mímica de una cara" pues "el objetivo no miente", y la uniformidad de la reducción llevándola al séptimo: "existiendo esta reducción matemática, comprenderán ustedes que la altura y el ancho de la cara, en el retrato de frente, y las dimensiones de la oreja, en el de perfil, bastan para destruir cualquier semejanza fisiognomónica". ${ }^{6}$

El mantenimiento de las pautas bertillonianas en el sistema adoptado por las policías regionales evidenció la pervivencia de la necesidad de dotar al sujeto de una "imagen real" independientemente de la eficiencia misma del procedimiento. Por ello el debate sobre la conservación del retrato hablado y la fotografía resultó más extenso que el sostenido sobre la propia funcionalidad que debían cumplir los métodos. Precisamente, pese a la exactitud de las huellas dactilares en la identificación, las mismas no dotaban al sujeto de una identidad que lo hiciera visible. No lo hacían una persona concreta, perdiéndose ese "rostro que cuenta toda una historia", que es personal pero también genérica, en este caso de un determinado delincuente de acuerdo a las tipologías criminológicas. ${ }^{47}$

Por otra parte, el abandono del uso de la imagen fotográfica, aparejaba la perdida de elementos esenciales de la personalidad del criminal que la criminología biológica detectaba. Si uno de los objetivos fundamentales de los órganos de control social es el combate al delito, la escuela positivista influyó en dotar al delincuente de rasgos particulares. Incluso, de haberse tomado las formas más radicales en sus principios, las secuelas en las políticas de identificación de delincuentes, al establecer los rasgos físicos que objetivamente poseían los criminales, hubieran permitido la detención antes de la

\footnotetext{
45 Armand Ugon, E. y otros (1931). Leyes, Decretos y Disposiciones de Carácter Policial. 1825 - 1930 , Mdeo., s/e, T. II, p. 241. Debido a los altos costos esta solo sería enviada a pedido.

${ }^{46}$ Giribaldi, A. (1906). Op. Cit. p. 43 y 44.

${ }^{47}$ Penhos, Marta (2005). Frente y perfil. Fotografía y prácticas antropológicas y criminológicas en Argentina a fines del siglo XIX y principios del XX, p. 23. Debo el conocimiento del presente trabajo a Laura Malosetti.
} 
realización del hecho ilícito. ${ }^{48}$ Seguramente lo que pervivirá de esta idea central, es la posibilidad de realizar una identificación negativa ${ }^{49}$ del individuo como sujeto anormal, distinto de todos los demás.

Los avances de los procedimientos fotográficos terminaron por eliminar el problema de la ineficacia generada por las limitaciones técnicas. Sus progresos permitieron la "garantía de fidelidad de las imágenes" reposicionando a la fotografía en el uso de la represión policial. La "perfección casi absoluta" en lentes, la sensibilidad en las placas, la mayor rapidez en los "procedimientos químicos" para los negativos y la fijación permanente puede "consagrar sus excelencias" como mecanismo de identificación:

\begin{abstract}
á esta altura de nuestros progresos, cuando se hacen discursos para decirnos que el arte fotográfico no tiene aplicaciones en ciencia policial y que es una violencia el usarla -itan luego con los delincuentes! $Y$ se concluye aconsejando en pleno Congreso, reservar su empleo para los grandes criminales, precisamente en aquellos en los que se hace inútil todo procedimiento de identidad, porque la verdad yo no veo que exista ventaja alguna en retratar á un preso, condenado por ejemplo á 30 años de Penitenciaría, á no ser que se quiera conservar estos negativos con el objeto de obsequiar á sus nietos, con una ampliación de bromuro. ${ }^{50}$
\end{abstract}

La fotografía fue para ambas corrientes un elemento insustituible, fundamentalmente en su empleo por parte del agente policial en el momento de la persecución del delincuente: "la verdadera misión de las Oficinas de Identificación: facilitar al agente de investigaciones una filiación tan exacta y tan minuciosa que no pueda dejar la menor duda en su ánimo, acerca del que momentáneamente ha sido objeto de su misión". ${ }^{51}$

Ningún mecanismo, ni el dactiloscópico ni el antropométrico, pudo sustituir en la práctica a la imagen concreta del delincuente. Las mordaces críticas de Giribialdi y Sarachaga que pintan a la policía en la calle debatiéndose entre las dificultades para extraer la huella digital a cada ciudadano y los problemas para descifrar una tarjeta antropométrica para la búsqueda de un sujeto determinado, se remitirá al empleo de la fotografía como el método para "reconocer"..."y detener en medio de la muchedumbre á un sujeto". 52 "Más tarde”, ${ }^{, 53}$ la identificación volverá a ser un trabajo de gabinete.

\footnotetext{
${ }^{48}$ Speckman Guerra, Elisa (2003). El Derecho Penal en el porfiriato: un acercamiento en la legislación, los discursos y las prácticas, p. 205. Debo el conocimiento del presente trabajo a su autora.

49 Trinidad Fernández, P. (1991). Op. Cit., p. 292.

${ }^{50}$ Giribaldi, A. (1906). Op. Cit., p. 42.

${ }^{51}$ Giribaldi, A. (1905). Op. Cit., p. 38.

${ }^{52}$ Sarachaga, A. (1906). Op. Cit., p. 18 y 19.

53 Ibidem.
} 


\section{Conclusiones}

El último cuarto del siglo XIX, de la mano de la criminología positivista y su visión del criminal como una personalidad marcada por condicionamientos bio-sico-sociológicos, ${ }^{54}$ mostró el desarrollo y aplicación de nuevas técnicas de identificación. Si bien algunas de ellas recogerían el legado de métodos tradicionales, muchas veces reformulados, el destino de su aplicación sufrió un cambio radical. Así, tanto la impresión digital como la fotografía cobraron una importancia central en el uso policial como elemento de control de la criminalidad y en la práctica judicial especialmente para el registro de los antecedentes.

La fotografía colaboró además en la reafirmación de una visión del criminal que la criminología positivista había alimentado lo que se reflejó en las secciones policiales de la prensa muchas veces ilustradas con imágenes generadas desde las propias oficinas de identificación. Las técnicas fotográficas que desnudaban al individuo de todo elemento superfluo, en sentido contrario de la fotografía social, sacaban del criminal los rasgos más negativos de su imagen ratificando la excepcionalidad del individuo y su notoria peligrosidad. ${ }^{55}$ La fotografía ya estandarizada sería acompañada por un retrato hablado que procuraba evidenciar "lo peor" de cada sujeto. Cicatrices, arrugas, pliegues de la piel, son la antítesis del retrato social destacando lo que este busca ocultar. No es la "normalidad" sino las "anomalías regionales" la que conforman la "piedra angular de la policía científica". 56

Pero, la cuestión de la identificación de delincuentes, especialmente el problema de los reincidentes, "constituyó en los hechos la cabeza de puente de un proyecto general, más o menos consciente, de control generalizado y sutil sobre la sociedad". 57

La aplicación de estas técnicas se trasladará rápidamente al resto de los sectores de la sociedad. Progresivamente se fue desarrollando un creciente intercambio entre las

\footnotetext{
${ }^{54}$ Mantovani, Ferrando (1988). El siglo XIX y las ciencias criminales, Bogotá: Temis, Monografías Jurídicas, p. 21.

${ }_{55}$ Leon Leon, M. (1999-2000). Op. Cit., p. 10.

${ }^{56}$ Giribaldi, A. (1905). Op. Cit., p. 39.

${ }^{57}$ Guinzburg, Carlo (1994). Mitos, emblemas, indicios. Morfología e historia. 2. ed., Barcelona: Gedisa, p. 159.
} 
policía de los diversos países que vieron crecer sus archivos. Al igual que en Europa, durante el primer lustro del siglo XX se sucedieron en el Cono Sur los acuerdos de "canje de antecedentes de individuos peligrosos" como ocurrió en 1903 entre las policías de La Plata, Buenos Aires, Río de Janeiro, Santiago de Chile y Montevideo. Todas ellas ya tenían montados sus respectivos gabinetes de identificación con un laboratorio fotográfico. Se resaltaba el valor insustituible de la fotografía en la persecución de criminales, reconociéndole también un papel destacado en la investigación tanto en lo que hace a la perpetuación de la prueba como al soporte de la información visual. ${ }^{58}$

El acuerdo rescataba los beneficios de que "toda persona honesta" se registre. Esto, cumpliría una doble finalidad, evitar "injustos vejámenes", pero fundamentalmente aportar un banco de información policial "útil en cualquiera circunstancia". ${ }^{9}$ Recordemos, que los métodos de identificación funcionan mediante el mecanismo de cotejo, o sea su capacidad se reduce a señalar que una imagen es igual a otra, por lo que el montaje de este archivo de información policial sería imprescindible, entre otros objetivos, en la identificación de los delincuentes primarios.

Un decreto complementario del acuerdo de 1905 estableció en Uruguay la obligatoriedad de la identificación del sistema dactiloscópico para los delincuentes, y su extensión a todos los funcionarios de la Dirección del Gabinete Policial de Identificación. ${ }^{60}$ La ley del 11 de mayo de 1914 universalizó la obligatoriedad del control mediante la creación de la cedula de identidad personal. Sugestivamente, su puesta en práctica no sólo se encontrará en manos de la Oficina de Identificación de la Policía de Montevideo, sino que se presenta como una ampliación de la ley del 12 de julio de 1912 que obliga a la identificación de detenidos y cadáveres de desconocidos. La propia norma mantiene vigente además del empleo del sistema dactiloscópico, la potestad de "recurrir en cuanto sea posible a los demás que hayan acreditado valor científico y resultados prácticos" 61

Así la difusión del sistema dactiloscópico, recomendada por el IV Congreso Científico reunido en Santiago de Chile en 1908, llevó a la instalación de servicios especializados, y a la extensión del uso de la huella digital, cada vez más omnipresente en los documentos. Sin embargo en la práctica policial y forense no se abandonaría

\footnotetext{
${ }^{58}$ Giraudo, Silvia; Arenas, Patricia (2004). Op. Cit., p. 125.

${ }^{59}$ Armand Ugon, E. y otros (1931). Op. Cit., T. II, p. 242.

60 Ibidem, p. 497 y 498.

${ }^{61}$ Otero y Mendoza, Gabriel (1929). Legislación del Uruguay vigente. 1825 - 1928 (extra códigos), Mdeo.: "El Siglo Ilustrado", p. 319.
} 
completamente el sistema antropométrico el que mantendrá aún una larga vida. Incluso, luego de la profunda transformación legal que significó la sanción de los Códigos Penales y del Niño en 1934, la praxis judicial conservó el empleo de la ficha de filiación donde se describen los caracteres morfológicos. En los expedientes judiciales y de oficinas especializas como el Consejo del Niño, ${ }^{62}$ paradigma del nuevo modelo de trato a la infancia, se continuó con la utilización del retrato hablado haciendo constar la raza, forma de cara, frente, cejas, labios, nariz, boca, mentón y orejas, junto a la impresión digito pulgar. De esta forma se contraviene la idea bastante extendida que "los gabinetes de Bertillon" tuvieron "corta vida"63 a partir de la aparición del sistema dactiloscópico de Vucetich.

Pero más allá del método empleado, la fotografía de frente y de perfil permanecerá en ellos omnipresente. La extensión del retrato fotográfico a muchos de los instrumentos identificatorios (carnés, pasaporte, registros cívicos, ${ }^{64}$ etc.) evidencian la comprensión de los responsables del orden público de las posibilidades que esta ofrecía como herramienta de control. Esto explica su presencia cada vez más extensa, no sólo en las practicas forenses sino como mecanismo de identificación universal.

La fotografía, y un conjunto importante de imágenes, se han ido incorporando paulatinamente a la vida diaria. Sus consecuencias parecen evidenciar la necesidad de profundizar en las investigaciones que han comenzado a realizar los historiadores del delito y el castigo.

\section{Referencias}

Armand Ugon, E. y otros (1931). Leyes, Decretos y Disposiciones de Carácter Policial. 1825 - 1930, Mdeo., s/e, T. II.

Bentham, Jeremy (2005). El panóptico, Bs. As.: Quadrata.

Bertillon, Alphonse (1890). Cómo se debe realizar un retrato judicial. Disponível em: www.educ.ar. Consultado el 13 de julio de 2014.

\footnotetext{
${ }^{62}$ Archivo General de la Nación - Consejo del Niño, carpetas 1934 - 1938.

63 Leon Leon, M. (1999-2000). Op. Cit., p. 10.

${ }^{64}$ El propio Vucetich en su novel cargo de Jefe del Gabinete de Identificación Dactiloscópica del Ministerio de Guerra argentino creado por las leyes de registro electoral y enrolamiento militar registró para las elecciones nacionales de 1912 más de un millón de matrículas individuales aplicando la clasificación por él ideada, reduciendo a un mínimo los votos impugnados y evitando los cuestionamientos por identidad como motivo.
} 
Bombonatti, José (s.d). Impressoes digitais. História da Dactiloscopia. Disponible en <www.coletoresimpress.com.br $>$. Consultado el 13 de julio de 2014.

Bustos Ramírez, Juan (1983). "Criminología y evolución de las ideas sociales". In Bergalli, Roberto y otros (1983). El pensamiento criminológico, un análisis crítico, Bogotá: Temis, v. I.

. "Estado y control: la ideología del control y el control de la ideología". In Bergalli, Roberto y otros (1983). El pensamiento criminológico, un análisis crítico, Bogotá: Temis, v. II.

Caimari, Lila (2004). Apenas un delincuente. Crimen, castigo y cultura en la Argentina, 1880 - 1955, Bs. As.: S. XXI editores.

De Arenaza, Carlos (s.d). Hogar de preservancia.

De La Cruz Lichet, Virginia (2004). Miradas enfrentadas (Indagaciones sobre la identidad a través del retrato fotográfico, 13 de diciembre, Universidad Complutense de Madrid, Seminario. Disponible en: <www.ucm.es>. Consultado el 15 de julio de 2014.

EL DÍA (1905), Montevideo, 13/11.

Ferri, Enrico (s.d.) Sociología criminal, Madrid: Centro Editorial de Góngora.

Foucault, Michel (2000). Los anormales, Bs. As.: F.C.E.

Freund, Gisèle (1946). La fotografía y las clases medias en Francia durante el siglo XIX, Bs. As.: Losada.

Garofalo, Rafaello (1912). La Criminología, estudio sobre la naturaleza del crimen y teoría de la penalidad, Madrid: Daniel Jarro.

Gayol, Sandra; Kessler, Gabriel (2002). Violencias, delitos y justicias en la Argentina, Bs. As.: Manantial Universidad Nacional de General Sarmiento.

Giraudo, Silvia; Arenas, Patricia (2004). Científicos europeos en el altiplano bolivianoargentino: antropología, expedición y fotos, Instituto de Arqueología y Museo. Universidad Nacional de Tucumán en Anales del Museos de América, 12.

Giribaldi, Alfredo (1905). Identidad y filiaciones, Mdeo.: Barreiro y Ramos.

(1906). Contribución al tópico médico-legal de la identidad. Extracto de la polémica, Mdeo.: El Siglo llustrado.

Guinzburg, Carlo (1994). Mitos, emblemas, indicios. Morfología e historia. 2. ed., Barcelona: Gedisa. 
Leon Leon, Marco Antonio (1999-2000). "Una impresión imborrable de su personalidad". La fotografía carcelaria y la identificación criminológica en Chile (1870 - 1940)". In Revista Chilena de Historia del Derecho, n. 18, Centro de Investigaciones de Historia del Derecho, Facultad de Derecho de la Universidad de Chile, Santiago.

López Rodríguez, José Ramón (1992). "Procedimientos de archivo". In Revista Photovision, n. 24, p. 6-14. Disponible en: <www.museodeandalucia/textos>. Consultado el 3 de julio de 2014.

Mantovani, Ferrando (1988). El siglo XIX y las ciencias criminales, Bogotá: Temis.

Otero y Mendoza, Gabriel (1929). Legislación del Uruguay vigente. 1825 - 1928 (extra códigos), Mdeo.: "El Siglo Ilustrado".

Penhos, Marta (2005). "Frente y perfil. Fotografía y prácticas antropológicas y criminológicas en Argentina a fines del siglo XIX y principios del XX". In Arte y antropología en la Argentina, Buenos Aires: Fundación Telefónica/Fundación Espigas/FIAAR.

Rojas Martínez, José Luis (1997). Las tarjetas de visita, popularización del retrato fotográfico en el México del siglo XIX. Disponible en: <www.mexicodesconocido.com>. Consultado el 20 de julio de 2014.

Salvatore, Ricardo (2004). "Criminología positivista, reforma de prisiones y la cuestión social/obrera en Argentina". In Suriano, Juan (Comp.) (2004). La cuestión social en Argentina 1870 - 1943. 2. ed., Bs. As.: La Colmena.

Sánchez Vigil, Juan M.; Fernández Fuentes, Belén (2005). "La fotografía como documento de identidad". In Documentación de las Ciencias de la Información, v. 28. Disponible en: $<$ www.ucm.es $>$. Consultado el 8 de julio de 2014.

Sappietro, Eugenio L. (2000). "El sistema dactiloscópico argentino”. In Studia Croatica, n. 141. Disponible en: <www.studiacroatica.com>. Consultado el 25 de julio de 2014.

Sarachaga, Alejandro (1906). Dactiloscopía y convenio internacional de policía, Mdeo.: El Siglo llustrado.

Speckman Guerra, Elisa (2001). La identificación de criminales y los sistemas ideados por Alphonse Bertillon: discursos y prácticas (Ciudad de México 1895 - 1913). In Historia y grafia, n. 17, p. 99-129.

. (2003). El Derecho Penal en el porfiriato: un acercamiento en la legislación, los discursos y las prácticas, México: Instituto de Investigaciones Jurídicas, UNAM, p. 201212.

Trinidad Fernández, Pedro (1991). La defensa de la sociedad. Cárcel y delincuencia en España (siglos XVIII-XX), Madrid: Alianza. 
Turnes, Antonio (2005). "Cien años de la dactiloscopía en Uruguay". In Suplemento de Derecho Médico. Disponible en: <www.ddu.com>. Consultado el 25 de julio de 2014.

Vucetich, Juan (1901). Conferencia sobre el sistema dactiloscópico dada en la Biblioteca Pública de La Plata, La Plata, s/e. 